\title{
Fungos conidiais na Caatinga: espécies lignícolas
}

\author{
Alisson Cardoso Rodrigues da Cruz $^{1,2}$ e Luís Fernando Pascholati Gusmão ${ }^{1}$
}

Recebido em 15/05/2008. Aceito em 14/04/2009

RESUMO - (Fungos conidiais na Caatinga: espécies lignícolas). Um inventário de fungos conidiais foi realizado em seis áreas de extrema importância biológica do bioma Caatinga. Foram identificadas 41 espécies, com Dactylaria cazorlii Mercado, Gené \& Guarro e Thozetella queenslandica Paulus, P.Gadek \& K.D. Hyde descritas pela segunda vez para a ciência. Ellisembia bambusae (M.B. Ellis) W.P. Wu, Gonytrichum mirabile Hol.-Jech., Uberispora tropicalis Bhat \& W.B. Kendr. constituem novas ocorrências para o continente americano; Acrophragmis coronata Kiffer \& Reisinger, Bactrodesmium linderi (J.L. Crane \& Shearer) M.E. Palm \& E.L. Stewart, Piricauda cochinensis (Subram.) M.B. Ellis e Taeniolella alta (Ehrenb.) S. Hughes novas ocorrências para a América do Sul; Sporoschisma saccardoi E.W. Mason \& S. Hughes e Stachylidium bicolor var. bicolor Link novas ocorrências para o Brasil e Paraceratocladium bacilliformis Calduch, Stchigel, Gene \& Guarro nova citação para o semi-árido brasileiro. As novas ocorrências são descritas, ilustradas e comentadas e é incluída uma lista com as demais espécies encontradas.

Palavras-chave: Biodiversidade, fungos anamórficos, serapilheira, taxonomia

ABSTRACT - (Conidial fungi from Caatinga: lignicolous species). An inventory of the conidial fungi was carried in six areas of extreme biological importance of the Caatinga biome. Forty one species were identified: Dactylaria cazorlii Mercado, Gené \& Guarro and Thozetella queenslandica Paulus, P.Gadek \& K.D. Hyde are described the second time for science; Ellisembia bambusae (M.B. Ellis) W.P. Wu, Gonytrichum mirabile Hol.-Jech., Uberispora tropicalis Bhat \& W.B. Kendr. constitute new records for the American continent; Acrophragmis coronata Kiffer \& Reisinger, Bactrodesmium linderi (J.L. Crane \& Shearer) M.E. Palm \& E.L. Stewart, Piricauda cochinensis (Subram.) M.B. Ellis, Taeniolella alta (Ehrenb.) S. Hughes are new records for South America; Sporoschisma saccardoi E.W. Mason \& S. Hughes and Stachylidium bicolor var. bicolor Link are new records for Brasil and Paraceratocladium bacilliformis Calduch, Stchigel, Gene \& Guarro is a new record for the Brazilian semi-arid region. The new records are described, illustrated and commented and a check list with all species found is included.

Key words: Anamorphic fungi, biodiversity, taxonomy, leaf litter

\section{Introdução}

A região semi-árida corresponde a cerca de $60 \%$ do nordeste brasileiro (CNRBC 2004) e é marcada pelo déficit hídrico, originado tanto pelas baixas precipitações anuais (300-1000 mm/ano), irregulares e concentradas (3-6 meses), quanto pela evapotranspiração potencial elevada (1500-2000 $\mathrm{mm} / \mathrm{ano}$ ) que, juntamente com as altas temperaturas, determinam a fisionomia da região (Prado 2003).

Estudos recentes no bioma Caatinga têm revelado uma biota diversa, comparada às outras florestas tropicais secas da América do Sul (Giulietti et al. 2002; Rodrigues 2003; Rosa et al. 2003; Queiroz 2006). Porém, apenas 1\% da sua área está sob proteção integral em unidades de conservação, sendo considerado o bioma brasileiro mais vulnerável (Leal et al. 2005). Em 2002, o Ministério do Meio Ambiente indicou 82 áreas prioritárias para conservação nesse bioma, das quais 27 foram classificadas como de extrema importância biológica, o que representa um avanço em termos de reconhecimento da Caatinga como patrimônio nacional a ser preservado.

A diversidade de fungos na Caatinga também se mostra elevada (Gusmão \& Maia, 2006), sendo componentes importantes da micobiota os fungos conidiais. Estes, assim como representantes da fase sexual, decompõem preferencialmente os polissacarídeos da madeira e parecem ter pouca capacidade para decompor a lignina (Dix \& Webster 1995). As diferentes frações da serapilheira têm estrutura e composição química distintas e, portanto, são decompostas em diferentes velocidades (Cianciaruso et al. 2006). A porção mais lignificada é menos digerível e a sua decomposição depende dos poucos organismos que podem degradar os compostos lignocelulósicos (Hammel 1997).

Estudos com fungos conidiais lignícolas, apesar de dispersos, vêm revelando novos gêneros e espécies (Goos 1970; Holubová-Jechová 1972; Holubová-Jechová 1984; Nawawi \& Kuthubutheen 1989; Ho et al. 2000; Cai et al. 2003; Zhu et al. 2005; Kodsueb et al. 2006; Hu et al. 2007; Wongsawas et al. 2008). No Brasil, alguns autores investigaram substratos lignificados, mas uma pequena quantidade de fungos conidiais foi referida, com destaque para os trabalhos de Batista et al. (1960a;b, 1965, 1967), Grandi \& Gusmão (2001), Calduch et al. (2002) e Castañeda-Ruiz et al. (2003a). No semi-árido, novas espécies e novos registros de fungos conidiais lignícolas foram propostos, recentemente, por Castañeda-Ruiz et al. (2006), Marques et al. (2007) e Barbosa et al. (2007), ampliando o conhecimento sobre a ocorrência e a distribuição desses fungos na região que, mesmo assim, carece de inventários sobre a micobiota.

O objetivo desse trabalho foi descrever e ilustrar novas ocorrências de fungos conidiais lignícolas em áreas de extrema importância biológica no semi-árido brasileiro.

\section{Materiais e métodos}

No período de agosto de 2006 a fevereiro 2007 foram realizadas coletas da serapilheira em cada uma das seis áreas de extrema importância biológica do bioma Caatinga (MMA2002). As seis áreas estão distribuídas nos seguintes estados: Bahia (1) Região do Médio São Francisco (mun. Pilão Arcado), (2) Raso da Catarina (mun. Jeremoabo e Paulo Afonso), (3) Região de Senhor do Bonfim (mun. Campo Formoso e Senhor do Bonfim); Pernambuco (4) Região de Buíque/Vale do Ipojuca (mun. Buíque); Piauí(5) Parque Nacional Serra das Confusões (mun. Caracol); Rio Grande do Norte (6) Região de Seridó/Borborema (mun. Serra Negra do Norte).

\footnotetext{
1 Universidade Estadual de Feira de Santana, Departamento de Ciências Biológicas, Laboratório de Micologia,Feira de Santana, BA, Brasil

2 Autor para correspondência: alissonbio@yahoo.com.br
} 
Cinco amostras compostas contendo galhos, cascas e frutos secos, originadas de cada área de coleta foram submetidas à técnica de lavagem (Castañeda-Ruiz 2005) e mantidas em câmaras-úmidas que foram conservadas em temperatura ambiente e observadas durante 20 dias. As estruturas reprodutivas dos fungos conidiais foram coletadas com auxílio de agulhas de ponta fina e colocadas em meio de montagem permanente com resina PVL (álcool polivinílico + lactofenol). As lâminas foram depositadas no Herbário da Universidade Estadual de Feira de Santana (HUEFS).

\section{Resultados e discussão}

Acrophragmis coronata Kiffer \& Reisinger, Revue Ecol. \& Biol. Sol 7: 16. 1970.

Fig. 1-2

Conidióforos macronemáticos, mononemáticos, eretos, retos ou flexuosos, septados, simples, lisos, castanhoescuros, ápices castanho-claros, 67-271 × 4-6 $\mu \mathrm{m}$. Células conidiogênicas monoblásticas, terminais, proliferações percurrentes, lisas, castanho-claras. Conídios solitários, secessões rexolíticas, 2-septados, elípticos, células centrais mais largas com 6-9 protuberâncias hemisféricas formando um anel, secos, lisos, células basais e apicais castanho-claras, células centrais castanho-escuras, 12-13,5 × 9-10 $\mu \mathrm{m}$; células basais 3-3,5 $\mu \mathrm{m}$ larg.; apêndices flexuosos raramente presentes nas células apicais, unicelulares, simples, hialinos, 4-18 × 1,5-4 $\mu \mathrm{m}$.

Material examinado: BRASIL. Bahia: Senhor do Bonfim, fazenda Passaginha, sobre galho em decomposição, 3/X/2006, A.C.R. Cruz s.n. (HUEFS 130976).

Distribuição geográfica: China (Wu \& Zhuang 2005), Congo (Kiffer \& Reisinger 1970, Ellis 1976), Cuba (Mercado-Sierra \& Mena-Portales 1986).

Acrophragmis Kiffer \& Reisinger é caracterizado pela presença de conídios, originados a partir de células conidiogênicas anelídicas, com célula central mais larga e mais escura, com pequenas protuberâncias formando um anel (Wu \& Zhuang 2005). Os conidióforos do material examinado apresentaram dimensões maiores que as relatadas para a espécie (Kiffer \& Reisinger 1970; Ellis 1976; Mercado-Sierra \& Mena-Portales 1986; Wu \& Zhuang 2005). O gênero é composto por A. canadensis S. Hughes (Hughes 1979), A. coronata e A. reisingeri V.G. Rao \& A.P. Reddy (Rao \& Reddy 1978), sendo $A$. coronata a única a apresentar conídios 2-septados com protuberâncias hemisféricas. Acrophragmis laevispora Gamundí \& Aramb. (Gamundí et al. 1979) apresenta células conidiogênica tréticas e conídios sem protuberâncias, e atualmente é considerada sinônimo de Endophragmiella lignicola S. Hughes (Castañeda-Ruiz et al. 1997).

Bactrodesmium linderi (J.L. Crane \& Shearer) M.E. Palm \& E.L. Stewart, Mycotaxon 15: 319. 1982.

Bas.: Trichocladium linderi J.L. Crane \& Shearer, Mycologia 70(4): 866. 1978.

Fig. 3-4

Conidióforos micronemáticos, esporodoquiais, flexuosos, septados, simples, lisos, hialinos. Células conidiogênicas monoblásticas, terminais, lisas, hialinas. Conídios solitários, com secessões rexolíticas, 1-septados, raros 2-septados, obpiriformes, simples, lisos, células basais castanho-claras ou hialinas, células apicais castanho-escuras a negras, em mucilagem, lisos, 21-27 × 16-23 $\mu \mathrm{m}$; células basais 1,5-4,5 $\times 4,5-8 \mu \mathrm{m}$.

Material examinado: BRASIL. Bahia: Pilão Arcado, Barra do Iu, sobre casca em decomposição, 15/II/2007, A.C.R. Cruz s.n. (HUEFS 130977); Pilão Arcado, Barra do Iu, sobre casca em decomposição, 18/II/2007, A.C.R. Cruz s.n. (HUEFS 130978); Pilão Arcado, Brejinho, sobre galho em decomposição, 14/II/2007, A.C.R. Cruz s.n. (HUEFS 130979).

Distribuição geográfica: Austrália (Hyde \& Goh 1998), China (Farr et al. 2007), Estados Unidos da América (Crane \& Shearer 1978).

Bactrodesmium Cooke apresenta atualmente cerca de 40 espécies (Markovskaja 2006). O gênero é heterogêneo e inclui espécies com conídios pseudoseptados, como $B$. rahnii M.B. Ellis (Ellis 1976) ou euseptados, com ou sem a presença de bandas negras nos septos. Raramente são verrucosos, como B. palmicola Mercado, Heredia \& J. Mena (Mercado-Sierra et al. 1995) ou com septos longitudinais, como B. indicum Reghuveer (Rao 1983). As dimensões dos conídios do espécime brasileiro estão de acordo com as apresentadas por Crane \& Shearer (1978) e Palm \& Stewaet (1982). Bactrodesmium atrum M.B. Ellis, B. globosum Hol.Jech. e $B$. palmicola são similares a $B$. linderi pela presença de célula apical castanha-escura a negra, mas diferenciam-se pelo maior número de septos, maiores dimensões e verrucosidade nos conídios, respectivamente. Um ponto controverso no gênero é o tipo de secessão do conídio, sendo referidas tanto espécies esquizolíticas como rexolíticas. Zucconi \& Lunghini (1997) examinaram a espécie-tipo do gênero e determinaram a sua condição esquizolítica, sugerindo a revisão das espécies rexolíticas.

Dactylaria cazorlii Mercado, Gené \& Guarro, Mycol. Res. 104: 1404. 2000.

Fig. 5-6

Conidióforos macronemáticos, mononemáticos, eretos, retos ou flexuosos, septados, simples, lisos, castanhos, 30$58,5 \times 3-3,5 \mu \mathrm{m}$; bases geralmente arredondadas, 4,5-7 $\mu \mathrm{m}$ larg. Células conidiogênicas holoblásticas, monoblásticas, terminais, simpodiais, cilíndricas, denticuladas, lisas, castanho-claras a subhialinas. Conídios solitários, 2-5-septados, elipsóides, subclavados, levemente curvos, simples, secos, lisos, hialinos, 10,5-26 × 3-4,5 $\mu \mathrm{m}$.

Material examinado: BRASIL. Bahia: Paulo Afonso, IBAMA, sobre casca em decomposição, 30/VIII/2007, A.C.R. Cruz s.n. (HUEFS 130980).

Distribuição geográfica: Espanha (Gené et al. 2000).

Dactylaria Sacc. é composto atualmente por 94 espécies destacando-se a revisão de De Hoog (1985), com 41 espécies, 
e as compilações de Goh \& Hyde (1997), com 37 espécies e de Paulus et al. (2003), com 14 espécies. As espécies mais relacionadas à Dactylaria cazorlli são D. crinospora (G.F. Atk.) U. Braun \& Crous, que apresenta conídios 1-4 septados (Crous \& Braun 2003), D. leptospermi J.A. Cooper (Cooper 2005) e D. plovercovensis Goh \& K.D. Hyde que apresentam conídios 3-septados. Dactylaria crinospora difere pela forma (cilíndrico-filiforme a subfusifome) e pelas maiores dimensões dos conídios. O material brasileiro possui conidióforos menores quando comparado ao do espécime-tipo (Gené et al. 2000).

Ellisembia bambusae (M.B. Ellis) W.P. Wu, in Wu \& Zhuang, Fung. Divers. Res. Ser. 15: 109, 2005.

Bas.: Sporidesmium bambusae M.B. Ellis, Mycol. Pap. 103: 43. 1965.

Sin.: Imimyces bambusae (M.B. Ellis) A. Hern. Gut. \& B. Sutton, Mycol. Res. 101(2): 203. 1997.

Imicles bambusae (M.B. Ellis) Shoemaker \& Hambl., Can.

J. Bot. 79(5): 598. 2001.

Fig. 7-8

Conidióforos macronemáticos, mononemáticos, retos ou flexuosos, septados, simples, lisos, castanho-escuros, 35-77,5 $\times 4,5-7,5 \mu \mathrm{m}$. Células conidiogênicas holoblásticas, monoblásticas, terminais, integradas, determinadas ou raramente com proliferações percurrentes doliformes, cilíndricas a lageniformes, lisas, castanho-escuras. Conídios solitários, com proliferações 8-12(-16)-pseudoseptados, obclavados, bases truncadas, retos ou curvos, simples, secos, células da base castanhas, células medianas castanho-claras, células apicais subhialinas, 72,5-90 × 10-12,5 $\mu \mathrm{m}$; bases 3,5-5,5 $\mu \mathrm{m}$ larg.

Material examinado: BRASIL. Bahia: Pilão Arcado, Brejinho, sobre casca em decomposição, 14/II/2007, A.C.R. Cruz s.n. (HUEFS 131003).

Distribuição geográfica: China (Wu \& Zhuang 2005), Índia, Serra Leoa, Taiwan (Hernández-Gutiérrez \& Sutton 1997).

Ellisembia Subram. foi proposto a partir de Sporidesmium Link e abriga espécies que possuem conídios pseudoseptados, com células conidiogênicas determinadas ou com proliferação percurrente lageniforme a doliforme (Subramanian 1992). O espécime estudado apresentou a maioria das células conidiogênicas com crescimento determinado. As proliferações percurrentes observadas não apresentaram diferenças na coloração em relação às demais células do conidióforo, como descrito em Hernández-Gutiérrez \& Sutton (1997). Apesar de mais estreitos, os conídios do espécime brasileiro são mais semelhantes aos descritos por Hernández-Gutiérrez \& Sutton (1997) do que aos apresentados por Wu \& Zhuang (2005) que descreveram os conídios com apêndices filiformes, aseptados e envoltos por uma bainha mucilaginosa.

Gonytrichum mirabile Hol.-Jech., in Gams \& HolubováJechová, Stud. Mycol. 13: 84. 1976

Fig. 9-10
Conidióforos macronemáticos, mononemáticos, eretos, flexuosos, ápices helicoidais, septados, irregularmente ramificados, lisos, castanhos, 225-325 × 3-3,5 $\mu \mathrm{m}$. Ramificações flexuosas, ápices helicoidais ou curvos, septadas, lisas, castanhas, 78,5-255 × 3-5 $\mu \mathrm{m}$. Células conidiogênicas enteroblásticas, fialídicas, laterais, solitárias ou em grupos de 2-3, evidentes, determinadas, lageniformes, lisas, castanho-claras, 5-11,5 $\times$ 2,5-5 $\mu \mathrm{m}$. Conídios solitários, 0-septados, elípticos, simples, em mucilagem, lisos, hialinos, 2-3 × 1-2 $\mu \mathrm{m}$.

Material examinado: BRASIL. Bahia: Senhor do Bonfim, fazenda Passaginha, sobre casca em decomposição, 20/ IX/2006, A.C.R. Cruz s.n. (HUEFS 130987).

Distribuição geográfica: República Tcheca (Gams \& Holobová-Jechová 1976).

Gonytrichum Nees ex Wallr. é caracterizado por possuir conidióforos castanhos, simples ou ramificados, com extremidades estéreis, apresentando um colar de células onde são produzidas as fiálides, conídios 0 -septados, envoltos em mucilagem e hialinos (Hughes 1951; Gams \& HolobováJechová 1976). Atualmente seis espécies e cinco variedades são aceitas no gênero (Saccardo 1886; Hughes 1951; Hughes 1958; Barron \& Bhatt 1967; Gams \& Holobová-Jechová 1976; Holubová-Jechová 1982). Gonytrichum mirable apresenta conidióforos ramificados e é a única espécie que não produz fiálides associadas a um colar de células no conidióforo. Os conídios são menores que os descritos por Gams \& Holobová-Jechová (1976), entretanto a presença de ramificações flexuosas com ápices helicoidais, ou curvos, permite identifica-la como G. mirable. A espécie foi coletada apenas na sua localidade-tipo, sendo este o segundo registro da espécie para a ciência.

Paraceratocladium bacilliformis Calduch, Stchigel, Gene et Guarro, Mycologia 94: 1074. 2002.

Fig. 11-12

Setas eretas, retas ou flexuosas, septadas, simples, acerosas, lisas, castanho-escuras, 140-261 × 3,5-6 $\mu \mathrm{m}$. Conidióforos micronemáticos, mononemáticos, aderidos às setas, flexuosos, septados, simples, lisos, subhialinos, 1-2 $\mu \mathrm{m}$ larg. Células conidiogênicas enteroblásticas, fialídicas, laterais e terminais, evidentes, determinadas, lageniformes, lisas, subhialinas, 4-11 × 2,4-3,6 $\mu \mathrm{m}$. Conídios solitários, 0 -septados, baciliformes ou cilíndrico-alantóides, simples, em mucilagem, lisos, hialinos, 3-4,5 × 0,5-1 $\mu \mathrm{m}$.

Material examinado: BRASIL. Bahia: Jeremoabo, sobre casca em decomposição, 19/I/2007, A.C.R. Cruz s.n. (HUEFS 118031).

Distribuição geográfica: Brasil (Calduch et al. 2002).

Paraceratocladium R.F. Castañeda possui seis espécies e os principais caracteres taxonômicos são as morfologias da seta e a forma e septação dos conídios. O gênero ocorre em serapilheira submersa, como P. malaysianum Goh \& K.D. Hyde (Goh \& Hyde 2000) e em restos vegetais no solo, como P. polysetosum R.F. Castañeda (Castañeda-Ruiz 1987). 

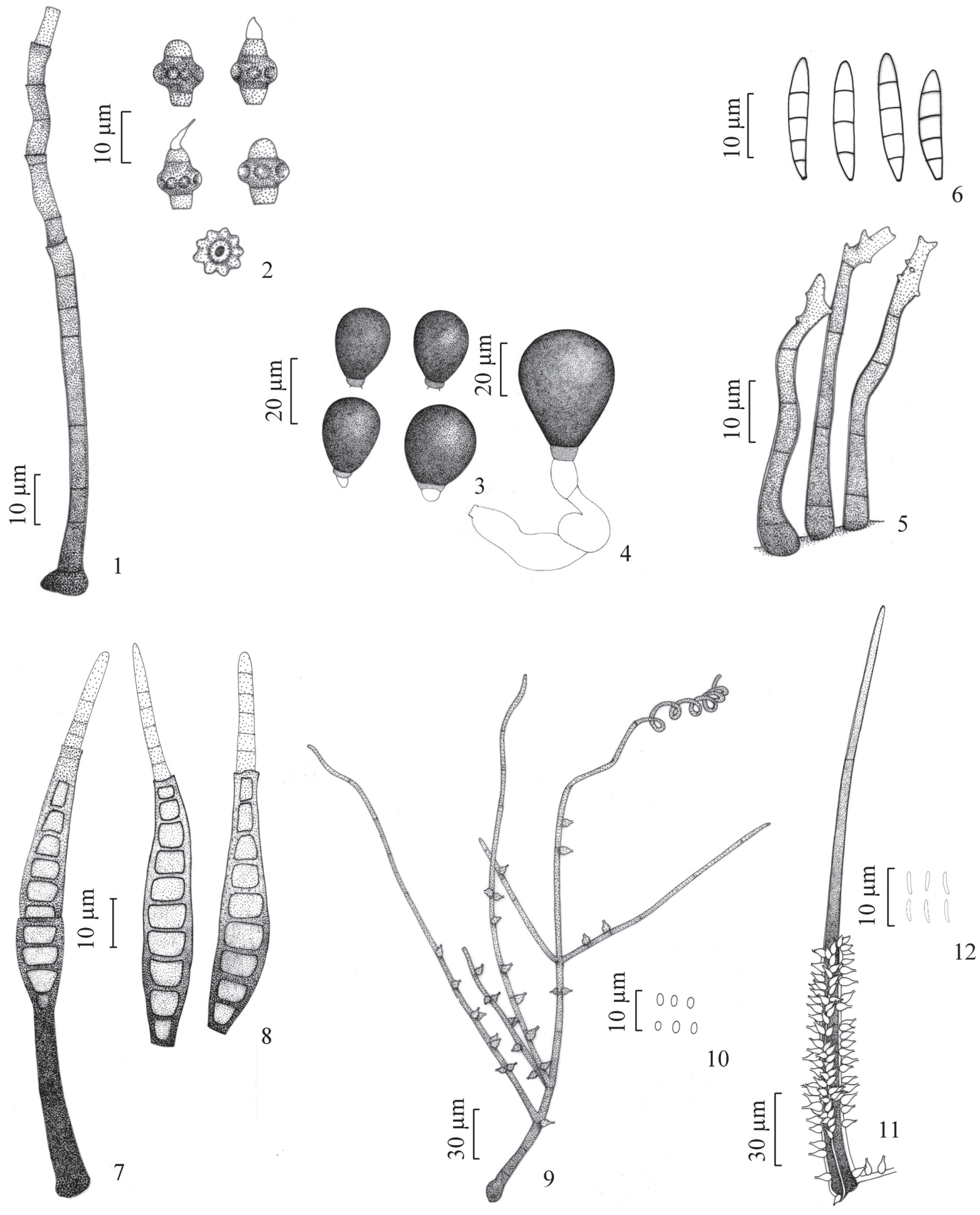

Figuras 1-12. 1-2. Acrophragmis coronata Kiffer \& Reisinger. 1. Conidióforo. 2. Conídios. 3-4. Bactrodesmium linderi (J.L. Crane \& Shearer) M.E. Palm \& E.L. Stewart. 3. Conídios. 4. Conidióforo e conídios. 5-6. Dactylaria cazorlii Mercado, Gené \& Guarro. 5. Conidióforo. 6. Conídios. 7-8. Ellisembia bambusae (M.B. Ellis) W.P. Wu. 7. Conidióforo. 8. Conídios. 9-10. Gonytrichum mirabile Hol.-Jech. 9. Conidióforo. 10. Conídios. 11-12. Paraceratocladium bacilliformis Calduch, Stchigel, Gené \& Guarro. 11. Conidióforo. 12. Conídios. 
Ocorre tanto decompondo folhas, P. triseptata Dulym., W. Wu \& Peerally (Dulymamode et al. 1998), como sobre substratos lignificados, $P$. bacilliformis (Calduch et al. 2002). As células conidiogênicas do espécime coletado são maiores em comprimento quando comparadas às descritas no espécime coletado no Rio de Janeiro (Calduch et al. 2002). Paraceratocladium bacilliformis apresenta setas simples e difere das demais espécies pelos conídios unicelulares baciliformes. Além de Paraceratocladium bacilliformis, foram coletadas no Brasil P. polysetosum (Gusmão \& Barbosa 2003) e $P$. silvestre R.F. Castañeda (Cruz et al. 2007).

Piricauda cochinensis (Subram.) M.B. Ellis, More Dematiaceous Hyphomycetes: 367. 1976.

Bas.: Petrakia cochinensis Subram., Sydowia 1: 15. 1957. Fig. 13

Conidióforos e células conidiogênicas não observados. Conídios solitários, multiseptados, piriformes, ramificados, secos, base frequentemente verrucosa, castanho-escuros, 42-76,5 × 40,5-70,5 $\mu \mathrm{m}$, com 3-9 apêndices eretos, retos ou flexuosos, septados, simples, lisos, castanhos a castanhoclaros no ápice, 10-118,5 × 3,5-7,5 $\mu \mathrm{m}$.

Material examinado: BRASIL. Bahia: Campo Formoso, sobre espata de Syagrus coronata (Mart.) Becc. em decomposição, 1/VIII/2006, A.C.R. Cruz s.n. (HUEFS 130989).

Distribuição geográfica: Cuba (Mercado-Sierra et al. 1997), Etiópia (Bhat \& Sutton 1985), Índia (Ellis 1976), Japão (Nakagiri \& Ito 1995), China, Malásia, Ilhas Seicheles (Farr et al. 2007), México (Heredia-Abarca et al. 1997).

Piricauda Bubák é composto por oito espécies e uma variedade (Mercado-Sierra et al. 2005). Apesar da não observação dos conidióforos e células conidiogênicas, o material examinado apresenta características típicas do gênero, como conídios muriformes e longos apêndices (Ellis 1971; Mercado-Sierra et al. 1997). Os conídios do material examinado são mais largos e apresentam apêndices maiores do que os espécimes descritos por Ellis (1971) e MercadoSierra et al. (1997; 2005). Piricauda longispora Mercado, Gené \& Guarro é a espécie mais próxima de $P$. cochinensis, podendo ser diferenciada desta pelo conídio fusiforme ou cilíndrico. O espécime-tipo de $P$. cochinensis foi coletado decompondo espata e esta espécie está fortemente associada a restos vegetais da família Palmae (Ellis 1976; HolubováJechová \& Mercado-Sierra 1989; Nakagiri \& Ito 1995; Heredia-Abarca et al. 1997)

Sporoschisma saccardoi E.W. Mason \& S. Hughes, in Hughes, Mycol. Pap. 31: 20. 1949.

Fig. 14-15

Hifas capitadas retas ou flexuosas, septadas, lisas, castanhas, 114-207 × 6-7,5 $\mu \mathrm{m}$, ápices arredondados 7,5-11,5 $\mu \mathrm{m}$ larg. Conidióforos macronemáticos, mononemáticos, associados a uma ou duas hifas capitadas, eretos, retos ou flexuosos, septados, simples, lisos, castanho-escuros,
204-270 × 8,5-11,5 $\mu \mathrm{m}$; ventre 13,5-16,5 $\mu \mathrm{m}$ larg. Células conidiogênicas enteroblásticas, fialídicas, terminais, integradas, castanho-escuras. Conídios em cadeia, 5-septados, geralmente constritos nos septos, células centrais mais largas em relação às células das extremidades, cilíndricos, simples, secos, lisos, castanho-escuros nas células centrais e castanhoclaros nas células das extremidades, 37,5-46,5 × 10-12 $\mu \mathrm{m}$.

Material examinado: BRASIL. Bahia: Senhor do Bonfim, sobre casca em decomposição, 12/X/2006, A.C.R. Cruz s.n. (HUEFS 130994).

Distribuição geográfica: África do Sul, Brunei, China, Malásia (Goh et al. 1997), Austrália (Matsushima 1989), antiga União das Repúblicas Socialistas Soviéticas, Índia (Farr et al. 2007), Canadá (Stalpers 2007), Estados Unidos da América (Raja et al. 2007), Gana (Hughes 1952), México (Heredia-Abarca et al. 2004), Itália (Nag Raj \& Kendrick 1975), Tailândia (Lumyong et al. 2003), Taiwan (Matsushima 1980), Venezuela (Castañeda-Ruiz et al. 2003b).

Sporoschisma Berk. \& Broome apresenta sete espécies descritas (Goh et al. 1997). Os caracteres de maior valor taxonômico são o número de septos, morfologia, ornamentação e coloração dos conídios. As dimensões do espécime estudado são semelhantes às descritas por Goh et al. (1997), exceto pela largura menor do ventre da célula conidiogênica. Sporoschisma nigroseptatum D. Rao \& R. Rao possui conídios 5-septados; entretanto, as mensurações dos conidióforos e conídios a diferenciam de S. saccardoi (Rao \& Rao 1964; Goh et al. 1997).

Stachylidium bicolor var. bicolor Link, Mag. Ges. Naturf. Fr. Berlin 3: 15. 1809.

Sin.: Dematium verticillatum Hoffm., Deutschlands Flora oder Botanisches Taschenbuch 3: 2. 1795.

Botrytis bicolor (Link) Pers., Mycologia europaea 1: 37. 1822.

Stachylidium bicolor Link ex Fr. Systema mycologicum 3: 391. 1832.

Acrostalagmus olivaceus Corda, Icon. fung. 2: 15. 1838.

Acremonium bicolor (Link ex Fr.) Bon., Handbuch der allgeeinen Mykologie. 92. 1851.

Stachylidium olivaceum (Corda) Sacc., Syll. fung. 4: 332. 1886.

Stachylidium fuscum Cooke \& Ellis, Grevillea 8: 12. 1879. Fig. 16-17

Conidióforos macronemáticos, mononemáticos, retos ou flexuosos, septados, ramificados, verruculosos, castanhos, ápices castanho-claros, 135-225 × 2,5-4,5 $\mu \mathrm{m}$. Ramificações retas, septadas, dispostas em verticilos, verruculosas, castanho-claras, 24-39 × 3-4 $\mu \mathrm{m}$. Células conidiogênicas enteroblásticas fialídicas, laterais e terminais, verticiladas, evidentes, determinadas, cilíndricas, verrucolosas, castanhoclaras, 11,5-19,5 × 2-4 $\mu \mathrm{m}$. Conídios solitários, 0-septados, elípticos, com uma cicatriz basal, simples, em mucilagem olivácea, subhialinos, 3,5-6 × 1,5-2,5 $\mu \mathrm{m}$. 
Material examinado: BRASIL. Bahia: Pilão Arcado, sobre fruto em decomposição, 2/III/2007, A.C.R. Cruz s.n. (HUEFS 130995).

Distribuição geográfica: Belize (Morris 1978), Canadá, China, Ilhas Seicheles, Papua-Nova Guiné (Farr et al. 2007), Costa do Marfim (Rambelli et al. 2004), Costa Rica (Morris 1972), Cuba (Mercado-Sierra 1984), Espanha, Nepal, Turquia (Stalpers 2007), Estados Unidos da América (como Stachylidium fuscum, Hughes 1951), Hungria (Révay 1998), Inglaterra, Gana, Malásia, Serra Leoa (Hughes 1951), Japão (Matsushima 1975), México (Heredia-Abarca et al. 2004), Nova Zelândia (Hughes 1978), Reino Unido (Ellis et al. 1950), República Tcheca (como Stachylidium olivaceum, Hughes 1951), Tailândia (Lumyong et al. 2003), Taiwan (Matsushima 1980), Uganda (Hansford 1943), Venezuela (Castañeda-Ruiz et al. 2003b).

Stachylidium Link foi proposto em 1809 para acomodar duas espécies, S. terrestre Link e S. bicolor Link. O gênero é facilmente reconhecido pelas células conidiogênicas monofiálidicas verticiladas, com colarete inconspícuo. Os conidióforos e células conidiogênicas verruculosos não foram reportados por Hughes (1951) e Mercado-Sierra et al. (1997) relataram que essa condição apresentou-se rara no material cubano. Stachylidium bicolor var. bicolor pode ser diferenciado de S. bicolor var. caespitosum Hol.-Jech. pelos conidióforos comumente agrupados e pelos conídios cilíndricos (Mercado-Sierra et al. 1997). Stachylidium griseum Berl. é a única espécie registrada para o Brasil (Luna $\&$ Cordeiro-Neto 1971).

Taeniolella alta (Ehrenb.) S. Hughes, Can. J. Bot. 36: 817. 1958.

Bas.: Hormiscium altum Ehrenb., Sylv. mycol. berol. (Berlin): $10,22.1817$

Sin.: Torula alta (Ehrenb.) Pers., Mycol. Europ., 1:22. 1822. Taeniola alta (Ehrenb.) Bon., Handb.: 36. Stuttgart. 1851. Torula alnea Peck, Rep. N.Y. St. Mus. nat. Hist. 25: 89. 1873. Septonema dichaenoides Peck \& Cooke, in Peck, Rep. N.Y.

St. Mus. nat. Hist. 30: 53. 1878.

Septonema nitidum P. Karst., Meddn Soc. Fauna Flora fenn. 16: 44.1888.

Fig. 18-19

Conidióforos macronemáticos, mononemáticos, retos ou flexuosos, septados, simples, lisos, castanho-escuros a avermelhados, 22,5-75 × 8-15,5 $\mu \mathrm{m}$. Células conidiogênicas holoblásticas, monoblásticas, terminais, integradas, determinadas, cilíndricas, lisas, castanho-escuras. Conídios em cadeia, (2-)3(-6) septados, geralmente 3-septados, elíptico-truncados, retos ou levemente curvos, simples, secos, células basais e apicais castanhas, células medianas castanho-escuras, 17,5-42,5 × 7,5-12,5 $\mu \mathrm{m}$.

Material examinado: BRASIL. Bahia: Pilão Arcado, sobre casca em decomposição, 16/II/2007, A.C.R. Cruz s.n. (HUEFS 130996).
Distribuição geográfica: antiga União das Repúblicas Socialistas Soviéticas (Farr et al. 2007), Bielorrússia (Yurchenko 2001), Estados Unidos da América, Canadá (Hughes 1980), França, Suíça (Stalpers 2007), Hungria (Révay 1985).

Taeniolella S. Hughes possui conidióforos geralmente curtos, simples ou ramificados na base, com células conidiogênicas holoblásticas, produzindo conídios em cadeia, lisos ou verrucosos, uni a multiseptados. Taeniolella alta pode apresentar conídios com mais de $10 \mu \mathrm{m}$ de larg. como T. breviuscula (Berk. \& M.A. Curtis) S. Hughes, T. exilis (P. Karst.) S. Hughes e T. rudis (Sacc.) S. Hughes. Entretanto T. breviuscula difere por possuir septos transversais e longitudinais, T. exilis possui conídios 1-3 septados com parede grossa e T. rudis apresenta conídios 5-8 septados (Ellis 1971; 1976). Segundo Hughes (1980) as dimensões dos conídios de T. alta apresentam grande variação coerente com o material examinado. Diederich (1992) descreveu duas espécies associadas a liquens e comentou que muitas espécies com conídios verrucosos estão associadas a esses organismos.

Thozetella queenslandica Paulus, P.Gadek \& K.D. Hyde, Mycologia 96: 1081. 2004.

Fig. 20-22

Esporodóquios dispersos, superficiais, massas de conídios brancas a castanho-claras envolvendo os conidióforos. Conidióforos macronemáticos, densamente agrupados, retos ou flexuosos, septados, ramificados, lisos, subhialinos a castanho-claros, 75-89,5 × 2-3 $\mu \mathrm{m}$. Células conidiogênicas enteroblásticas monofialídicas, terminais, integradas, determinadas, cilíndricas, lisas, subhialinas, 10-22 $\times 2-3 \mu \mathrm{m}$; microarestas uncinadas, ápices verrucosos, 17-27 × 2,5-4 $\mu \mathrm{m}$. Conídios solitários, 0 -septados, lunados, simples, lisos, em mucilagem, hialinos, 11-14 × 1-2 $\mu \mathrm{m}$; sétulas filiformes, uma em cada extremidade, 4-6,5 $\mu \mathrm{m}$ comp.

Material examinado: BRASIL. Pernambuco: Buíque, sobre galho em decomposição, 28/VIII/2006, A.C.R. Cruz s.n. (HUEFS 130997).

Distribuição geográfica: Austrália (Paulus et al. 2004).

Thozetella Kuntze apresenta atualmente 14 espécies (Paulus et al. 2004, Allegrucci et al. 2004), caracterizadas pela presença de uma estrutura estéril, a microaresta, que é produzida e liberada juntamente com os conídios. O conidioma em esporodóquio e as microarestas uncinadas com ápice verrucoso determinaram a identificação da espécie. Thozetella havanensis R.F. Castañeda e T. buxifolia Allegr., Cazau, Cabello \& Aramb. são as espécies mais próximas, no entanto diferem por apresentar conidioma em sinema e microarestas sigmóides, além de conídios com maiores dimensões (Castañeda-Ruiz 1984; Allegrucci et al. 2004).

Uberispora tropicalis Bhat \& W.B. Kendr., Mycotaxon 49: 73. 1993.

Fig. 23-24

Conidióforos macronemáticos, mononemáticos, retos ou flexuosos, septados, ramificados, lisos, castanho-claros, 105- 

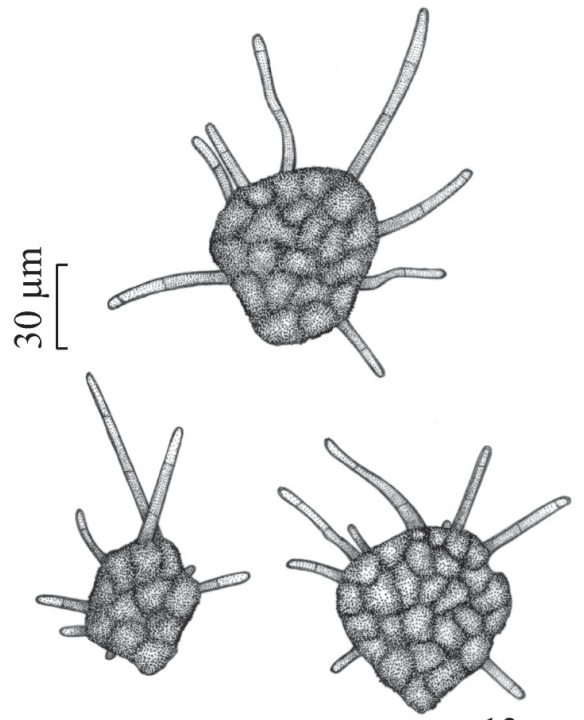

13
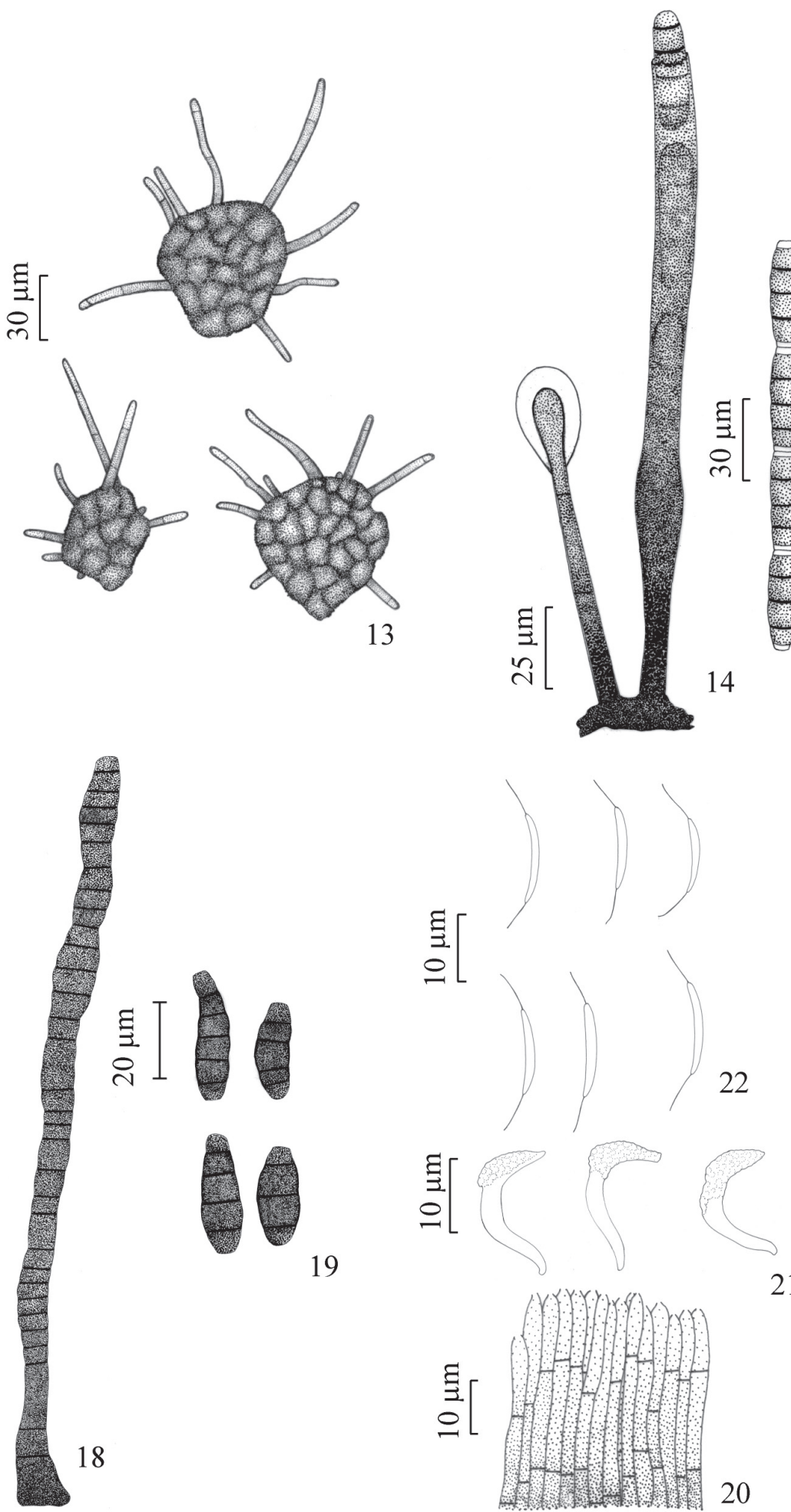

19
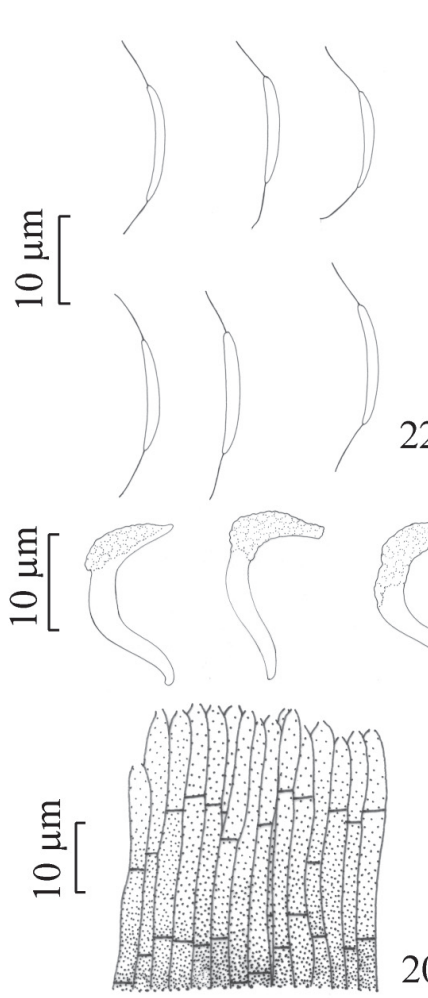

22

15

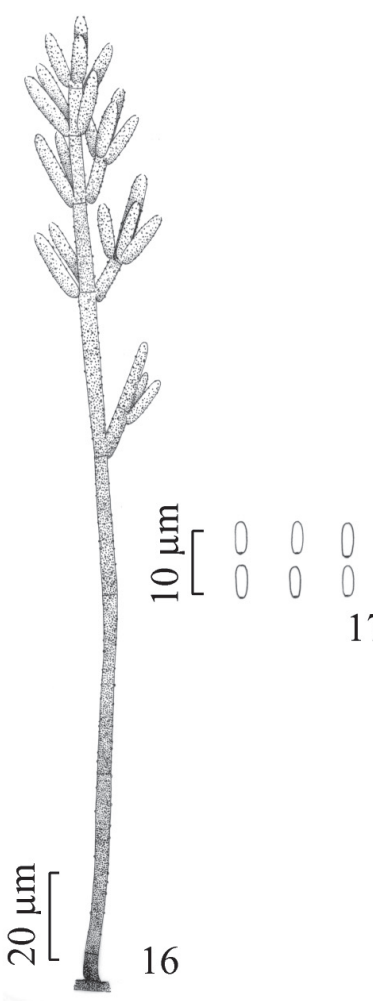

21

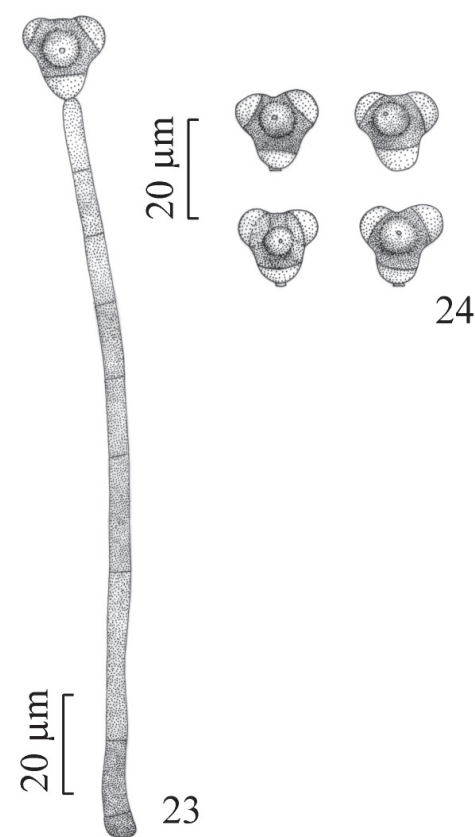

Figuras 13-24. 13. Piricauda cochinensis (Subram.) M.B. Ellis. 13. Conídios. 14-15. Sporoschisma saccardoi E.W. Mason \& S. Hughes. 14. Conidióforo. 15. Conídios. 16-17. Stachylidium bicolor var. bicolor Link. 16. Conidióforo. 17. Conídios. 18-19. Taeniolella alta (Ehrenb.) S. Hughes. 18. Conidióforo. 19. Conídios. 20-22. Thozetella queenslandica Paulus, P.Gadek \& K.D. Hyde. 20. Detalhe das células conidiogênicas. 21. Microarestas. 22. Conídios. 23-24. Uberispora tropicalis Bhat \& W.B. Kendr. 23. Conidióforo. 24. Conídios. 
162,5 × 4,5-6,5 $\mu \mathrm{m}$. Células conidiogênicas holoblásticas, monoblásticas, terminais, integradas, com proliferações percurrentes, cilíndricas, lisas, castanho-claras. Conídios solitários, 3-septados, ramificados, secos, 15-16,5 $\mu$ m diâm.; células basais castanho-claras 4,5-6 × 7,5-9 $\mu \mathrm{m}$; células satélites castanhoclaras 3-4,5 × 7,5-9 $\mu \mathrm{m}$; células centrais castanho-escuras.

Material examinado: BRASIL. Bahia: Senhor do Bonfim, fazenda Passaginha, sobre casca em decomposição, 20/ IX/2006, A.C.R. Cruz s.n. (HUEFS 130998).

Distribuição geográfica: Coréia do Sul (Mel'nik \& Shin 2005), Índia (Bhat \& Kendrick 1993).

Uberispora Piroz. \& Hodges possui três espécies descritas, U. heteroseptata R.F. Castañeda, Guarro \& Cano, U. simplex (Ichinoe) Piroz. \& Hodges e U. tropicalis. Os principais caracteres para distinção entre as espécies são a forma, a posição e a septação das células satélites dos conídios. Os conídios do material examinado apresentam a célula basal e as células satélites mais largas do que os espécimes descritos por Bhat \& Kendrick (1993) e Mel'nik \& Shin (2005). Uberispora tropicalis difere de U. simplex pela presença de células satélites obtusas e pela ausência de células apicais (Ellis 1976). Uberispora heteroseptata difere das demais espécies do gênero por apresentar células satélites frequentemente septadas (Castañeda-Ruiz et al. 1996).

\section{Lista das demais espécies encontradas}

Cacumisporium sigmoideum Mercado \& R.F. Castañeda, Acta Bot. Cubana 50: 1. 1987.

Material examinado: BRASIL. Bahia: Campo Formoso, Mata da Esterzinha, sobre galho em decomposição, 19/ IX/2006, A.C.R. Cruz s.n. (HUEFS 129310); Senhor do Bonfim, fazenda Passaginha, sobre fruto em decomposição, 02/X/2006, A.C.R. Cruz s.n. (HUEFS 129309).

Chalara alabamensis Morgan-Jones \& E.G. Ingram, Mycotaxon 4(2): 489. 1976.

Material examinado: BRASIL. Bahia: Jeremoabo, Mata das Pororocas, sobre casca em decomposição, 18/I/2007, A.C.R. Cruz s.n. (HUEFS 129313).

Chloridium virescens var. virescens (Pers.) Gams \& Hol.Jech., Stud. Mycol. 13: 17. 1976.

Material examinado: BRASIL. Bahia: Pilão Arcado, sobre casca em decomposição, 06/III/2007, A.C.R. Cruz s.n. (HUEFS 129314); Senhor do Bonfim, Serra da Maravilha, sobre galho em decomposição, 12/X/2006, A.C.R. Cruz s.n. (HUEFS 129315).

Cryptophiale kakombensis Piroz., Can. J. Bot. 46: 1124. 1968.

Material examinado: BRASIL. Bahia: Jeremoabo, Mata das Pororocas, sobre casca em decomposição, 18/I/2007, A.C.R. Cruz s.n. (HUEFS 129318).
Dictyochaeta britannica (M.B. Ellis) Whitton, McKenzie \& K.D. Hyde, Fungal Diversity 4: 137. 2000.

Material examinado: BRASIL. Bahia: Jeremoabo, Mata das Pororocas, sobre casca em decomposição, 17/I/2007, A.C.R. Cruz s.n. (HUEFS 129375).

Dictyochaeta fertilis (S. Hughes \& W.B. Kendr.) Hol.Jech., Folia Geobot. Phytotax. 19: 426. 1984.

Material examinado: BRASIL. Bahia: Senhor do Bonfim, sobre fruto em decomposição, 28/IX/2006, A.C.R. Cruz s.n. (HUEFS 129370); Senhor do Bonfim, fazenda Passaginha, sobre fruto em decomposição, 4/X/2006, A.C.R. Cruz s.n. (HUEFS 129371).

Dictyochaeta novae-guineensis (Matsush.) A.I. Romero, Boln. Soc. argent. Bot. 22: 76. 1983.

Material examinado: BRASIL. Bahia: Campo Formoso, Mata da Esterzinha, sobre casca em decomposição, 4/X/2006, A.C.R. Cruz s.n. (HUEFS 129365).

Dictyochaeta obesispora (S. Hughes \& W.B. Kendr.) Whitton, McKenzie \& K.D. Hyde, Fungal Diversity 4: 145. 2000 .

Material examinado: BRASIL. Bahia: Senhor do Bonfim, Serra da Maravilha, sobre casca em decomposição, 11/X/2006, A.C.R. Cruz S.n. (HUEFS 129373).

Dictyochaeta simplex (S. Hughes \& W.B. Kendr.) Hol.Jech., Folia geobot. phytotax. 19: 434. 1984.

Material examinado: BRASIL. Bahia: Paulo Afonso, sobre fruto em decomposição, 28/I/2007, A.C.R. Cruz s.n. (HUEFS 129362).

Ellisembia adscendens (Berk.) Subram., Proc. Indian natn Sci. Acad., Part B. Biol. Sci. 58: 183. 1992.

Material examinado: BRASIL. Bahia: Campo Formoso, Mata da Esterzinha, sobre casca em decomposição, 12/X/2006, A.C.R. Cruz s.n. (HUEFS 129332); Senhor do Bonfim, sobre galho em decomposição, 19/IX/2006, A.C.R. Cruz s.n. (HUEFS 129333).

Gonytrichum chlamydosporium var. chlamydosporium G.L. Barron \& G.C. Bhatt, Mycopath. Mycol. appl. 32: 126. 1967.

Material examinado: BRASIL. Bahia: Pilão Arcado, sobre casca em decomposição, 14/II/2007, A.C.R. Cruz s.n. (HUEFS 141557); Senhor do Bonfim, fazenda Passaginha, sobre casca em decomposição, 20/IX/2006, A.C.R. Cruz s.n. (HUEFS 141558); Senhor do Bonfim, fazenda Passaginha, sobre fruto em decomposição, 04/X/2006, A.C.R. Cruz s.n. (HUEFS 141559); Pernambuco: Buíque, sobre galho em decomposição, 17/VIII/2006, A.C.R. Cruz s.n. (HUEFS 129338).

Gyrothrix microsperma (Höhn.) Piroz., Mycol. Pap. 84: 14. 1962.

Material examinado: BRASIL. Bahia: Jeremoabo, próximo a casa 3, sobre fruto em decomposição, 1/II/2007, 
A.C.R. Cruz s.n. (HUEFS 129342); Senhor do Bonfim, fazenda Passaginha, sobre fruto em decomposição, 27/X/2006, A.C.R. Cruz s.n. (HUEFS 129344).

Helicosporium aureum (Corda) Linder, Ann. Mo. bot. Gdn. 16: 279. 1929.

Material examinado: BRASIL. Bahia: Pilão Arcado, sobre casca em decomposição, 16/II/2006, A.C.R. Cruz s.n. (HUEFS 129346); Senhor do Bonfim, Distrito de Carrapichel, sobre galho em decomposição, 9/X/2006, A.C.R. Cruz s.n. (HUEFS 129347).

Helicosporium griseum Berk. \& M.A. Curtis, Grevillea 3: 51. 1874.

Material examinado: BRASIL. Bahia: Jeremoabo, sobre fruto em decomposição, 18/I/2007, A.C.R. Cruz s.n. (HUEFS 129350); Senhor do Bonfim, sobre fruto em decomposição, 28/IX/2006, A.C.R. Cruz s.n. (HUEFS 129351); Senhor do Bonfim, sobre galho em decomposição, 28/IX/2006, A.C.R. Cruz s.n. (HUEFS 129352).

Helicosporium panacheum R.T. Moore, Mycologia 46: 92. 1954.

Material examinado: BRASIL. Bahia: Jeremoabo, Mata das Pororocas, sobre casca em decomposição, 16/I/2007, A.C.R. Cruz S.n. (HUEFS 129348); Senhor do Bonfim, fazenda Passaginha, sobre casca em decomposição, 5/X/2006, A.C.R. Cruz s.n. (HUEFS 129349).

Helicosporium pannosum (Berk. \& M.A. Curtis) R.T. Moore, Mycologia 49: 582. 1957.

Material examinado: BRASIL. Bahia: Senhor do Bonfim, fazenda Passaginha, sobre fruto em decomposição, 5/X/2006, A.C.R. Cruz s.n. (HUEFS 129354).

Helicosporium virescens (Pers.) Sivan., Bitunicate Ascomycetes and their Anamorphs: 591-592. 1984.

Material examinado: BRASIL. Bahia: Campo Formoso, Mata da Esterzinha, sobre galho em decomposição, 19/ IX/2006, A.C.R. Cruz s.n. (HUEFS 129355); Jeremoabo, sobre casca em decomposição, 17/I/2007, A.C.R. Cruz s.n. (HUEFS 129356); Senhor do Bonfim, Distrito de Carrapichel, sobre espata de Syagrus coronata (Mart.) Becc. em decomposição, 9/X/2006, A.C.R. Cruz s.n. (HUEFS 129357); Senhor do Bonfim, Serra da Maravilha, sobre casca em decomposição, 11/X/2006, A.C.R. Cruz s.n. (HUEFS 129358).

Memnoniella echinata (Rivolta) Galloway, Trans. Br. mycol. Soc. 18: 165. 1933.

Material examinado: BRASIL. Bahia: Pilão Arcado, Barra do Iu, sobre fruto em decomposição, 6/III/2007, A.C.R. Cruz s.n. (HUEFS 129386).

Moorella speciosa P.Rag. Rao \& D. Rao, Mycopathologia 22: 52.1964.
Material examinado: BRASIL. Bahia: Pilão Arcado, Barra do Iu, sobre casca em decomposição, 14/II/2006, A.C.R. Cruz s.n. (HUEFS 129361).

Myrmecridium schulzeri var. schulzeri (Sacc.) Arzanlou, W. Gams \& Crous, Stud. Mycol. 58: 84. 2007.

Material examinado: BRASIL. Bahia: Jeremoabo, Mata das Pororocas, sobre casca em decomposição, 18/I/2007, A.C.R. Cruz s.n. (HUEFS 131001).

Myrothecium verrucaria (Alb. \& Schwein.) Ditmar, Deutschl. Fl., Abt. III (Pilze Deutschl.) 1-1: 7. 1813.

Material examinado BRASIL. Bahia: Paulo Afonso, sobre semente em decomposição, 28/I/2007, A.C.R. Cruz s.n. (HUEFS 129405).

Periconia cookei E.W. Mason \& M.B. Ellis, Mycol. Pap. 56: 72.1953.

Material examinado: BRASIL. Bahia: Paulo Afonso, sobre fruto em decomposição, 14/I/2007, A.C.R. Cruz s.n. (HUEFS 129413).

Pithomyces chartarum (Berk. \& M.A. Curtis) M.B. Ellis, Mycol. Pap. 76: 13. 1960.

Material examinado: BRASIL. Bahia: Paulo Afonso, sobre fruto em decomposição, 14/I/2007, A.C.R. Cruz s.n. (HUEFS 129422).

Pleurothecium recurvatum (Morgan) Höhn., Zentbl. Bakt. Parasitkde, Abt. II 60: 26. 1923.

Material examinado: BRASIL. Bahia: Senhor do Bonfim, fazenda Passaginha, sobre casca em decomposição, 2/X/2006, A.C.R. Cruz s.n. (HUEFS 129427).

Pseudobotrytis terrestris (Timonin) Subram., Proc. Indian Acad. Sci. Sect. B. 43: 277. 1956.

Material examinado: BRASIL. Bahia: Senhor do Bonfim, fazenda Passaginha, sobre casca em decomposição, 20/ IX/2006, A.C.R. Cruz s.n. (HUEFS 129428).

Repetophragma filiferum (Piroz.) R.F. Castañeda, Gusmão \& Heredia, Mycotaxon 95: 269. 2006.

Material examinado: BRASIL. Bahia: Campo Formoso, Mata da Esterzinha, sobre espata de Syagrus coronata (Mart.) Becc. em decomposição, 5/X/2006, A.C.R. Cruz s.n. (HUEFS 129429); Senhor do Bonfim, fazenda Passaginha, sobre galho em decomposição, 4/X/2006, A.C.R. Cruz s.n. (HUEFS 129430).

Stachybotrys globosa P.C. Misra \& S.K. Srivast., Trans. Br. mycol. Soc. 78(3): 556. 1982.

Material examinado: BRASIL. Bahia: Pilão Arcado, Barra do Iu, sobre fruto em decomposição, 8/III/2007, A.C.R. Cruz s.n. (HUEFS 125381). 
Torula herbarum (Pers.) Link, Magazin Ges. naturf. Freunde, Berlin 3(1-2): 19. 1809.

Material examinado: BRASIL. Bahia: Senhor do Bonfim, sobre fruto em decomposição, 28/IX/2006, A.C.R. Cruz s.n. (HUEFS 129472).

Vermiculariopsiella immersa (Desm.) Bender, Mycologia 24: 412. 1932.

Material examinado: BRASIL. Bahia: Pilão Arcado, sobre pecíolo de Mauritia flexuosa L. em decomposição, 20/II/2007, A.C.R. Cruz s.n. (HUEFS 129478).

\section{Agradecimentos}

Os autores agradecem ao Programa de Pesquisa em Biodiversidade do Semi-árido pelo suporte financeiro (PPBio Semi-árido/Ministério da Ciência e Tecnologia), aos Drs. Rafael Castañeda-Ruiz, David W. Minter, Gregorio Delgado, Josep Guarro, Kevin Hyde, Uwe Braun, Sayanh Somrithipol, Eric Mckenzie, Antonio Hernández-Gutiérrez e as Dras. Rosely Piccolo Grandi, Barbara Paulus, Astrid Ferrer e a Msc. Priscila Silva, pela generosidade no envio de literatura. O primeiro autor agradece ao Conselho Nacional de Desenvolvimento Científico e Tecnológico (CNPq) pela bolsa concedida, à Fundação de Amparo à Pesquisa do Estado da Bahia pelo apoio financeiro (Proc. APR071/2007) e ao Programa de Pós-graduação em Botânica (PPGBot/UEFS).

\section{Referências bibliográficas}

Allegrucci, N.; Cazau, M.C.; Cabello, M.N. \& Arambarri, A.M. 2004. Thozetella buxifolia sp. nov., a new Hyphomycete from Argentina. Mycotaxon 90: 275-279.

Barbosa, F.R.; Gusmão, L.F.P.; Castañeda-Ruiz, R.F.; Marques, M.F.O. \& Maia, L.C. 2007. Conidial fungi from the semi-arid Caatinga biome of Brazil. New species Deightoniella rugosa \& Diplocladiella cornitumida with new records for the neotropics. Mycotaxon 102: 39-49.

Barron, G.L. \& Bhatt, G.C. 1967. A new species of Gonytrichum from Soil. Mycopathologia et Mycologia Applicata 32: 126-128.

Batista, A.C.; Bezerra, J.L. \& Souza, R.G. 1960a. Algumas espécies de Helminthosporium Link. ex Fr. Publicações. Instituto de Micologia da Universidade do Recife 269: 1-27.

Batista, A.C.; Maia, H.S.; Lima, J.A. \& Matta, E.A.F. 1960b. Moniliales - descrição e revisão de algumas espécies. Atas do Instituto de Micologia. Universidade de Pernambuco, Recife 1: 247-274.

Batista, A.C.; Falcão, R.G.; Maciel, M.J.P. \& Maia, H. da Silva. 1965. Alguns Dematiaceae amerospóricos. Publicações. Instituto de Micologia da Universidade do Recife 447: 1-35.

Batista, A.C.; Ram, C.; Gillespie, L.R. \& Lima, V.M.O. 1967. Curious fungi associated with wood rotting in the state of Maranhão. Atas do Instituto de Micologia. Universidade Federal de Pernambuco, Recife 5: 25-41.

Bhat, D. \& Sutton, B. 1985. New and interesting hyphomycetes from Ethiopia Transactions of the British Mycological Society 85: 107-122.

Bhat, D.J. \& Kendrick, B. 1993. Twenty-five new conidial fungi from the western Ghat and Adaman Islands (India). Mycotaxon 49: 19-90.

Cai, L.; Zhang, K.Q.; McKenzie, E.H.C. \& Hyde, K.D. 2003. Freshwater fungi from bamboo and wood submerged in the Liput River in the Philippines. Fungal Diversity 13:1-12.

Calduch, M.; Gené, J.; Stchigel, A.M. \& Guarro, J. 2002. New species of Dictyochaetopsis and Paraceratocladium from Brazil. Mycologia 94: 1071-1077.

Castañeda-Ruiz, R.F. 1984. Nuevos taxones de Deuteromycotina: Arnoldiella robusta gen. et sp. nov., Roigiella lignicola gen. et sp. nov., Sporidesmium pseudolmediae sp.nov., y Thozetella havanensis sp. nov. Revista del Jardín Botánico Nacional 5: 57-87.

Castañeda-Ruiz, R.F. 1987. Fungi Cubenses II. Havana, Instituto de Investigaciones Fundamentales em Agricultura Tropical "Alejandro de Humboldt".
Castañeda-Ruiz, R.F. 2005. Metodologia en el estudio de los hongos anamorfos. Pp. 182-183. In: Anais do V Congresso Latino Americano de Micologia. Brasilia.

Castañeda-Ruiz, R.F.; Guarro, J. \& Cano, J. 1996. Notes on conidial fungi. IX. A new species of Uberispora from Cuba. Mycotaxon 59: 461-465.

Castañeda-Ruiz, R.F.; Guarro, J.; Figueras, M.J.; Gené, J. \& Cano, J. 1997. More conidial fungi from La Gomera, Canary Islands, Spain. Mycotaxon 65: 121-131.

Castañeda-Ruiz, R.F.; Guarro, J.; Velázquez-Noa, S. \& Gené, J. 2003a. A new species of Minimelanolocus and some hyphomycete records from rain forests in Brazil. Mycotaxon 85: 231-239.

Castañeda-Ruiz, R.F.; Iturriaga, T.; Minter, D.W.; Saikawa, M.; Vidal, G. \& Velázquez-Noa, S. 2003b. Microfungi from Venezuela, a new species of Brachydesmiella, a new combination, and new records. Mycotaxon 85: 211-229.

Castañeda-Ruiz, R.F.; Gusmão, L.F.P.; Heredia-Abarca, G. \& Saikawa, M. 2006. Some hyphomycetes from Brazil. Two new species of Brachydesmiella, two new combinations for Repetophragma, and new records. Mycotaxon 95: 261-270.

Cianciaruso, M.V.; Pires, J.S.R.; Delitti, W.B.C. \& Silva, E.F.L.P. 2006. Produção de serapilheira e decomposição do material foliar em um cerradão na Estação Ecológica de Jataí, município de Luiz Antônio, SP, Brasil. Acta Botanica Brasilica 20: 49-59.

CNRBC (Conselho Nacional da Reserva da Biosfera da Caatinga). 2004. Cenários para o bioma Caatinga. CNRBC, Secretaria de Ciência, Tecnologia e Meio Ambiente, Recife.

Cooper, J.A. 2005. New Zealand hyphomycete fungi: additional records, new species, and notes on interesting collections. New Zealand Journal of Botany 43: 323-349.

Crane, J.L. \& Shearer, C.A. 1978. Two new species of Trichocladium (Hyphomycetes) from submerged wood. Mycologia 70: 866-874.

Crous, P.W. \& Braun, U. 2003. Mycosphaerella and its anamorphs: 1. Names published in Cercospora and Passalora. CBS Biodiversity Series 1: 1-569.

Cruz, A.C.R.; Marques, M.F.O. \& Gusmão, L.F.P. 2007. Fungos anamórficos (Hyphomycetes) da Chapada Diamantina: novos registros para a Bahia e Brasil. Acta Botanica Brasilica 21: 847-855.

De Hoog, G.S. 1985. Taxonomy of the Dactylaria-Complex. IV. Dactylaria, Neta, Subulispora and Scolecobasidium. Studies in Mycology 26: 1-60.

Diederich, P. 1992. New or interesting Lichenicolous Fungi. 2. Taeniolella beschiana sp. nov. and Taeniolella serusiauxii sp. nov. (Hyphomycetes). Bulletin de la Société des naturalistes luxembourgeois 93: 155-162.

Dix, N.J. \& Webster, J. 1995. Fungal Ecology. London, Chapman \& Hall.

Dulymamode, R.; Wu, W. \& Peerally, A. 1998. Three new hyphomycetes on Pandanus leaves from Mauritius. Mycoscience 39: 285-291.

Ellis, M.B. 1971. Dematiaceous Hyphomycetes. Kew, Commonwealth Mycological Institute.

Ellis, M.B. 1976. More Dematiaceous Hyphomycetes. Kew, Commonwealt Mycological Institute.

Ellis, M.B.; Ellis, E.A. \& Ellis, P.E. 1950. British marsh and fen fungi. I. Transactions of the British Mycological Society 34: 147-169.

Farr, D.F.; Rossman, A.Y.; Palm, M.E. \& McCray, E.B. 2007. Fungal Databases, Systematic Botany \& Mycology Laboratory, ARS, USDA. Disponível em: http://nt.arsgrin.gov/fungaldatabases/. (Acesso em 23/novembro/2007).

Gams, W. \& Holobová-Jechová, V. 1976. Chloridium and some other dematiaceous hyphomycetes growing on decaying wood. Studies in Mycology 13: 1-97.

Gamundí, I.J.; Arambarri, A.M. \& Bucsinszky, A.M. 1979. Micoflora de la hojarasca de Nothofagus dombeyi, II. Darwiniana 22: 189-216.

Gené, J.; Mercado-Sierra, A. \& Guarro, J. 2000. Dactylaria cazorlii and Hansfordia catalonica, two new hyphomycetes from litter in Spain. Mycological Research 104: 1404-1407.

Giulietti, A.M.; Harley, R.M.; Queiroz, L.P.; Barbosa, M.R.V.; Bocage Neta, A.L. \& Figueredo, M.A. 2002. Plantas endêmicas da Caatinga. In: E.V.S.B. Sampaio; A.M. Giulietti, J. Virgínio \& C.F.L. GamarraRojas (eds.). Vegetação e flora das caatingas. Recife, APNE/CNIP.

Goh, T.K. \& Hyde, K.D. 1997. A revision of Dactylaria, with descrition of D. tunicata sp. nov. from submerged wood in Australia. Mycological Research 101: 1265-1272. 
Goh, T.K. \& Hyde, K.D. 2000. Paraceratocladium malaysianum sp. nov. (mitosporic fungi) from submerged wood in Malaysia. Nova Hedwigia 71: 95-100.

Goh, T.K.; Ho, W.H.; Hyde, K.D. \& Umali, T.E. 1997. New records and species of Sporoschisma and Sporoschismopsis from submerged wood in the tropics. Mycological Research 101: 1295-1307.

Goos, R.D. 1970. A new genus of the Hyphomycetes from Hawaii. Mycologia 62: 171-175.

Grandi, R.A.P. \& Gusmão, L.FP. 2001. Range extension of the mitosporic fungus Virgatospora echinofibrosa (Hyphomycetes) to Brazil. Revista de Biologia Tropical 49: 1269-1269.

Gusmão, L.F.P. \& Barbosa, F.F. 2003. Paraceratocladium polysetosum, a new record from Brazil. Mycotaxon 96: 151-154

Gismão, L.F.P. \& Maia, L.C. (ed.) 2006. Diversidade e caracterização dos fungos do Semi-Árido brasileiro. Recife, MCT/Associação Plantas do Nordeste.

Hammel, K.E. Fungal degradation of lignin. 1997. Pp. 33-46. In: G. Cadish \& K.E. Giller (Eds.). Driven by Nature: plant litter quality and decomposition. Walingford, CAB International.

Hansford, C.G. 1943. Contributions towards the fungus flora of Uganda. V. Fungi imperfecti. Proceedings of the Linnean Society 1: 34-67.

Heredia-Abarca, G., Mena-Portales, J., Mercado-Sierra, A. \& ReyesEstebanez, M. 1997. Tropical Hyphomycetes of Mexico. II. Some species from the Tropical Biology Station "Los Tuxtlas", Veracruz, Mexico. Mycotaxon 64: 203-223.

Heredia-Abarca, G.; Reyes-Estebanez, M. \& Arias-Mota, R.M. 2004. Adiciones al conocimiento de la diversidad de los hongos conidiales del Bosque Mesófilo de Montaña del Estado de Veracruz. Acta Botanica Mexicana 66: 1-22.

Hernández-Gutiérrez, A. \& Sutton, B.C. 1997. Imimyces and Linkosia, two new genera segregated from Sporidesmium sensu lato, and redescription of Polydesmus. Mycological Research 101: 201-209.

Ho, W.H.; Hodgkiss, I.J. \& Hyde, K.D. 2000. Cheiromyces lignicola, a new chirosporous anamorphic species from Hong Kong. Mycologia 92: $582-588$

Holubová-Jechová, V. 1972. Lignicolous Hyphomycetes from Czechoslovakia 1. Brachysporium. Folia Geobotanica \& Phytotaxonomica 7: 217-224.

Holubová-Jechová, V. 1982. New or interesting phialidic Hyphomycetes from Cuba. Mycotaxon 15: 277-292.

Holubová-Jechová, V. 1984. Bactrodesmiastrum, a new genus of lignicolous Hyphomycetes. Folia Geobotanica \& Phytotaxonomica 19: 103-106

Holubová-Jechová, V. \& Mercado-Sierra, A. 1989. Hyphomycetes from Loma de la Coca and some localities of la Habana and Matanzas provinces, Cuba. Acta Botanica Cubana 76: 1-15.

Hu, D.M.; Zhu, H.; Cai, L.; Hyde, K.D. \& Zhang, K.Q. 2007 Sirothecium triseriale, a new chirosporous anamorphic species from China. Cryptogamie Mycologie 28: 311-314.

Hughes, S.J. 1951. Stachylidium, Gonytrichum, Mesobotrys, Chaetopsis and Chaetopsella. Transactions of the British Mycological Society 34: $551-576$

Hughes, S.J. 1952. Fungi from the Gold Coast. I. Mycological Papers 48: 1-91.

Hughes, S.J. 1958. Revisiones Hyphomycetum Aliquot cum Appendice de Nominibus Rejeciendis. Canadian Journal of Botany 36: 727-836.

Hughes, S.J. 1978. New Zealand Fungi. 25. Miscellaneous species. New Zealand Journal of Botany 16: 311-370.

Hughes, S.J. 1979. Acrophragmis canadensis. Fungi Canadenses 143: 1-2.

Hughes, S.J. 1980. Taeniolella alta. Fungi Canadenses 184: 1-2.

Hyde, K.D. \& Goh, T.K. 1998. Fungi on submerged wood in Lake Barrine, north Queensland, Australia. Mycological Research 102: 739-749.

Kiffer, E. \& Reisinger, O. 1970. Contribution à l'étude de la microflore fongique du Congo I. - Champignons observés sur débris végétaux et sur pièges de cellulose. Revue D'Écologie et de Biologie du Sol 7: 11-31.

Kodsueb, R; Lumyong, S; Hyde, K.D.; Lumyong, P. \& Mckenzie, E.H.C. 2006. Acrodictys micheliae and Dicyosporium manglietiae, two new anamorphic fungi from woody litter of Magnoliaceae in northern Thailand. Cryptogamie Mycologie 27: 111-119.

Leal, I.R.; Silva, J.M.C.; Tabarelli, M. \& Lacher Jr., T.E. 2005. Mudando o curso da conservação da biodiversidade na Caatinga do Nordeste do Brasil. Megadiversidade 1: 139-146.
Lumyong, P.; Photita, W.; McKenzie, E.H.C.; Hyde, K.D. \& Lumyong, S. 2003. Saprobic fungi on dead wild banana. Mycotaxon 85: 345-346.

Luna, E.A. de \& Cordeiro-Neto, F. 1971. Observações sôbre o teste de Went em caldo de culturas fúngicas para assinalamento de auxinas. Publicações. Instituto de Micologia da Universidade Federal de Pernambuco 564: 1-16.

Markovskaja, S. 2006. A new species of Bactrodesmium from Lithuania. Mycotaxon 97: 337-343.

Marques, M.F.O.; Barbosa, F.R.; Gusmão, L.F.P.; Castañeda-Ruiz, R.F. \& Maia, L.C. 2007. Conidial fungi from the semi-arid Caatinga biome of Brazil. Cubasina microspora sp. nov., a note on C. albo-fusca, and some new records for South America. Mycotaxon 102: 17-23.

Matsushima, T. 1975. Icones Microfungorum a Matsushima Lectorum. Kobe, Published by the author.

Matsushima, T. 1980. Matsushima Mycological Memoirs n. 1. Kobe, Published by the author.

Matsushima, T. 1989. Matsushima Mycological Memoirs n. 6. Kobe, Published by the author.

Mel'nik, V.A. \& Shin, H.D. 2005. Rare species of anamorphic fungi recorded in Korea. Mikologiya i Fitopatologiya 39: 25-29.

Mercado-Sierra, A. 1984. Hifomicetes Demaciáceos de Sierra del Rosario, Cuba. Havana, Editorial Acadêmica.

Mercado-Sierra, A. \& Mena-Portales, J. 1986. Hifomicetes de Topes de Collantes, Cuba I. Especies Holoblásticas. Acta Botanica Hungarica 32: $189-205$

Mercado-Sierra, A.; Guarro, J. \& Heredia, G. 2005. The hyphomycete genus Piricauda, with the description of a new species. Mycological Research 109: 723-728.

Mercado-Sierra, A.; Heredia, G. \& Mena-Portales, J. 1995. New species of dematiaceous Hyphomycetes from Veracruz, Mexico. Mycotaxon 55: 491-499.

Mercado-Sierra, A.; Holubová-Jechová, V. \& Mena-Portales, J. 1997. Hifomicetos dematiáceos de Cuba, Enteroblásticos. Torino, Museo Regionale di Scienze Naturali, Monografie XIII.

MMA (Ministério do Meio Ambiente). 2002. Avaliação e identificação de áreas e ações prioritárias para a conservação, utilização sustentável e repartição dos benefícios da biodiversidade nos biomas brasileiros. Ministério do Meio Ambiente/Secretária de Biodiversidade e Florestas, Brasil.

Morris, E.F. 1972. Costa Rican Hyphomycetes. Mycologia 64: 887-896.

Morris, E.F. 1978. Belizean Hyphomycetes. Mycotaxon 7: 265-274.

Nag Raj, T.R. \& Kendrick, B. 1975. A monograph of Chalara and allied genera. Ontário, Wilfrid Laurier University Press.

Nakagiri, A. \& Ito, T. 1995. Some dematiaceous Hyphomycetes on decomposing leaves of Satakentia liukiunsis from Ishigaki Island Japan. Institute for Fermentation Reseach Communications 17: 75-98

Nawawi, A. \& Kuthubutheen, A.J. 1989. Canalisporium, a new genus of lignicolous hyphomycetes from Malaysia. Mycotaxon 34: 475-487.

Palm, M.E. \& Stewart, E.L. 1982. Two new combinations in Bactrodesmium. Mycotaxon 15: 319-325.

Paulus, B.; Gadek, P. \& Hyde, K.D. 2003. Two new species of Dactylaria (anamorphic fungi) from Australian rainforests and an update of species in Dactylaria sensu lato. Fungal Diversity 14: 143-156.

Paulus, B.; Gadek, P. \& Hyde, K. 2004. Phylogenetic and morphological assessment of five new species of Thozetella from an Australian rainforest. Mycologia 96: 1074-1087.

Prado, D.E. 2003. As caatingas da América do Sul. Pp. 3-73. In: I.R. Leal, M. Tabarelli \& J.M.C. Silva (eds.). Ecologia e conservação da Caatinga. Recife, Editora Universitária, Universidade Federal de Pernambuco.

Queiroz, L.P. 2006. The Brazilian Caatinga: Phytogeographical patterns inferred from distribution data of the Leguminosae. Pp: 113-149. In: R.T. Pennington; G.P., Lewis \& J. Ratter (eds.). Neotropical Savannas and Dry Forests: Plant Diversity, Biogeography, and Conservation. Oxford, Taylor \& Francis C.R.C. Press.

Raja, H.A.; Stchigel, A.M.; Miller, A.N.; Crane, J.L. \& Shearer, C.A. 2007. Hyphomycetes from the Great Smoky Mountains National Park, including three new species. Fungal Diversity 26: 271-286.

Rambelli, A.; Mulas, B. \& Pasqualetti, M. 2004. Comparative studies on microfungi in tropical ecosystems in Ivory Coast forest litter: behaviour on different substrata. Mycological Research 108: 325-336. 
Rao, D. \& Rao, P.R. 1964. Sporoschisma Berk. \& Br. from India. Mycopathologia et Mycologia Applicata 24: 81-84.

Rao, P.R. 1983. Two new species of Bactrodesmium from India. Indian Journal of Mycology and Plant Pathology 13: 207-208.

Rao, V.G. \& Reddy, K.A. 1978. Some new microfungi from India. Indian Journal Mycological Research 16: 301-309.

Révay, Á. 1985. Dematiaceous Hyphomycetes inhabiting forest debris in Hungary I. Studia Botanica Hungarica 18: 65-71.

Révay, Á. 1998. Review of the Hyphomycetes of Hungary. Studia Botanica Hungarica 27-28: 5-74.

Rodrigues, M.T. 2003. Herpetofauna da caatinga. Pp. 181-236. In: I.R. Leal, M. Tabarelli \& J.M.C. Silva (eds.). Ecologia e conservação da Caatinga. Recife, Editora Universitária, Universidade Federal de Pernambuco.

Rosa, R.S.; Menezes, N.A.; Britski, H.A.; Costa, W.J.E.M. \& Groth, F. 2003. Diversidade, padrões de distribuição e conservação dos peixes da Caatinga. Pp. 135-180. In: I.R. Leal; M. Tabarelli \& J.M.C. Silva (eds.). Ecologia e conservação da Caatinga. Recife, Editora Universitária, Universidade Federal de Pernambuco.

Saccardo, P.A. 1886. Syllogue Fungorum IV. Hyphomycetae. Padua.
Stalpers, J. 2007. Filamentous fungi database. CBS - Centraalbureau voor Schimmelcultures. Disponível em: http://www.cbs.knaw.nl/. (Acesso: 12/dezembro/2007).

Subramanian, C.V. 1992. A reassessment of Sporidesmium (Hyphomycetes) and some related taxa. Proceedings of the Indian National Sciences Academy 58: 179-190.

Wongsawas, M.; Wang, H.K.; Hyde, K.D. \& Lin, F.C. 2008. New and rare lignicolous hyphomycetes from Zhejiang Province, China. Journal of Zhejiang University Science B 9:797-801.

Wu, W. \& Zhuang, W. 2005. Sporidesmium, Endophragmiella and related genera from China. Fungal Diversity Research Series 15 . Hong Kong, Fungal Diversity Press.

Yurchenko, E.O. 2001. On some wood-inhabiting dematiaceous Hyphomycetes with remarkable conidia in Belarus. Mycena 1: 32-54.

Zhu, H; Cai, L; Hyde, K.D. \& Zhang, K.Q. 2005. A new species of Acrogenospora from submerged Bamboo in Yunnan, China. Mycotaxon 92: 383-386.

Zucconi, L. \& Lunghini, D. 1997. Studies on Mediterranean Hyphomycetes. VI. Remarks on Bactrodesmium, and B. cubense comb. nov. Mycotaxon 63: 323-327. 